Academic Platform Journal of Engineering and Science

\title{
Numerical Investigation for Moment-Curvature Relationship of CFRP Jacketed RC Columns
}

\author{
${ }^{1}$ M Nadir Olabi, *2Naci Caglar and ${ }^{3}$ Nurdan G. Koroglu \\ ${ }^{1}$ Institute for Natural Science, Civil Eng., Sakarya University, Sakarya, Turkey, mandhro@gmail.com, \\ ${ }^{2}$ Dep. of Civil Eng., Engineering Faculty, Sakarya University, Sakarya, Turkey, caglar@sakarya.edu.tr, \\ ${ }^{3}$ Institute for Natural Science, Civil Eng., Sakarya University, Sakarya, Turkey, nurdangulkoroglu@gmail.com, \\ Research Paper \\ Arrival Date: 28.06.2019 \\ Accepted Date: 27.11.2019
}

\begin{abstract}
External jacketing of columns with Carbon Fiber Reinforced Polymer (CFRP) sheets is one of the most commonly used techniques to strengthen the existing reinforced concrete (RC) columns subjected to earthquake loads. In this paper, a parametric study is performed to examine the effects of CFRP jacketing, axial load levels and concrete quality on the total response of the CFRP jacketed RC columns. The newly computer code was developed to determine moment-curvature relationships of CFRP jacketed RC columns. Moment curvature analysis is carried out using three column sections with a fixed reinforcement ratio and three different concrete qualities, and also three different thicknesses of the CFRP wraps. The performance of jacketed RC columns in terms of ductility, strength, stiffness and energy dissipation is investigated. The results of the parametric study showed that strengthening RC columns with CFRP wraps has a significant effect on the total response of jacketed columns due to the confinement of concrete. However, the degree of enhancement in total response is also related to axial load levels.
\end{abstract}

Keywords: Moment curvature; carbon fiber reinforced polymer; rectangular RC column; fiber model; GNU Octave

\section{INTRODUCTION}

The necessity of strengthening most of the reinforced concrete (RC) buildings have arisen in the last decades because recent major earthquakes caused significant casualties and severe damages to many buildings that were designed according to older codes [1-3]. Jacketing of RC columns is the major solution and frequently used method to strengthen older RC buildings. Various jacketing methods such as Fiber Reinforced Polymers (FRP) [2-8], steel jacket [9-10], concrete jacket [11] and ferrocement jacket [12-13] have been applied to strengthen RC columns subjected to earthquake loads. Fiber Reinforced Polymer (FRP) is referring to a range of newly developed fabrics that showed their ability to be one of the most important and practical jacketing materials used for strengthening $\mathrm{RC}$ structural elements. One of the frequently used FRP fabrics is Carbon Fiber Reinforced Polymer (CFRP). Several experimental and analytical researches have been carried out to study RC columns strengthened with CFRP [2-8]. By using high strength epoxy adhesives, it is easy and fast to strengthen RC columns by CFRP jackets to enhance their ductile and strength properties.

Wang et al. [2] studied 8 columns jacketed using CFRP to investigate the effect of high-strength concrete on the enhanced element, and the results were conducted at high and low axial forces. Castillo et al. [3] used anchors to fix FRP sheets and tested their capacity under cyclic lateral loads. Saribiyik [4] evaluated the effect of fiber types, layer numbers, and the use of hybrid fibers on concrete behavior. Juntanalikit et al. [5] performed an experimental and analytical study on non-ductile RC columns strengthened with CFRP to enhance the shear capacity and confinement. They showed that the shear strength and displacement capability of RC columns strengthened with CFRP under quasi-static cyclic loading is significantly higher than unstrengthened columns. Hosseini et. al. [6] carried out an experimental and analytical study on high-strength RC columns retrofitted with CFRP and moment-curvature relation was calculated numerically. Iacobucci et al. [7] investigated the seismic behavior of square RC columns wrapped with different layer numbers of CFRP. In both studies, they indicated that the performance of retrofitted columns with CFRP is noticeably improved as compared to RC columns with sufficient confinement due to lateral reinforcement, and also the behavior improvement is related to increasing wrap layers. Moreover, Hosseini et. al. numerical calculations were conservative compared to experimental data because of the conservative values of the concrete model used for stress-strain relationship. Many researchers [14-15] have studied to develop stress-strain models for concrete confined with CFRP to fully understand the behavior of CFRP jacketed RC columns. Youssef et. al. [14] and Teng et al. [15], separately, compared their proposed models to experimental results and showed good predictions of the behavior of FRP-confined concrete. 
The main goal of this study is to examine the effects of CFRP jacketing, axial load levels and concrete quality on the total response of the CFRP jacketed RC columns. For this purpose, moment-curvature analysis is performed based on newly developed computer code to investigate the behavior of CFRP jacketed RC columns subjected to higher and lower axial loads than the balanced point. A parametric study is carried out using three column sections with a fixed reinforcement ratio and three different concrete qualities, and also three different thicknesses of the CFRP wraps. The performance of jacketed RC columns in terms of ductility, strength, stiffness and energy dissipation is investigated.

\section{OVERVIEW OF MOMENT - CURVATURE RELATIONSHIP}

Curvature could be defined as a unit rotation angle and a geometrical parameter represents deformation and derived from the tangent with respect to arc length (Fig. 1).

$$
\begin{aligned}
& \varphi=\frac{d \theta}{d x}=\frac{d^{2} y}{d x^{2}}=\frac{1}{\rho}=\frac{\varepsilon_{c}}{c} \\
& \varphi=\frac{1}{\rho}=\frac{M}{E I}
\end{aligned}
$$

where $\varphi$ is curvature and $E I$ is flexural stiffness.

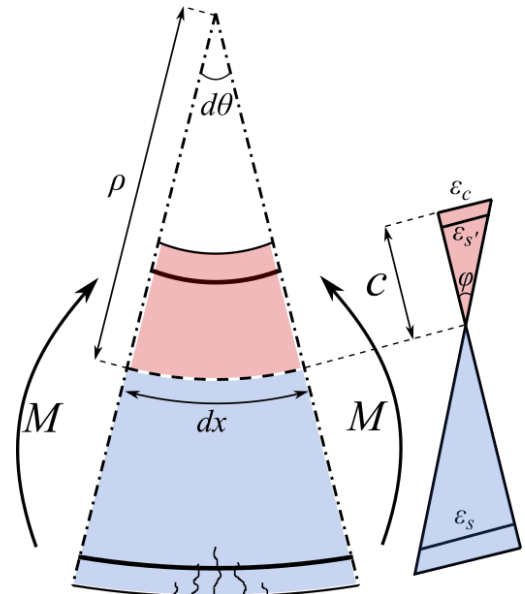

Fig. 1 Moment-Curvature Relationship

Moment-curvature relationship of a reinforced concrete (RC) section could exhibit the behavior of a $\mathrm{RC}$ member under pure bending or bending with axial load. This relationship could be obtained in either analytical or experimental methods. And by examining the momentcurvature relationship of a cross-section the capacity, rigidity and ductility characteristics of this section could be anticipated [16].

Analytical investigations are very essential to generate moment-curvature relationships for the in-test members since it is not convenient to make experiments whenever needed. By using computer coding based on equilibrium and compatibility equations and realistic material models, generating accurate moment-curvature relationships for $\mathrm{RC}$ sections is possible and achievable [17].

\section{FRP-CONFINED CONCRETE MODEL}

It is arisen to simulate material models accurately for determining a realistic relationship between curvature and moment of CFRP jacketed RC columns sections (Fig. 2). Many researchers had been studying to develop FRPconfined concrete material models for FRP jacketed RC columns [14-15]. FRP-confined concrete model proposed by Youssef et al. [14] was selected in this study.

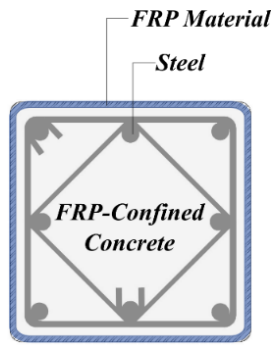

Fig. 2 Cross-section of CFRP jacketed RC column

In the FRP-confined concrete model proposed by Youssef et al. [14], the main parameters that describe the confinement model for rectangular columns (Fig. 3) are:

$$
\begin{aligned}
& \frac{f_{t}}{f_{c}^{\prime}}=1.0+1.1350\left(\frac{\rho_{j} E_{j} \varepsilon_{j t}}{f_{c}^{\prime}}\right)^{\frac{5}{4}} \\
& \varepsilon_{t}=0.002+0.0775\left(\frac{\rho_{j} E_{j} \varepsilon_{j t}}{f_{c}^{\prime}}\right)^{\frac{6}{7}}\left(\frac{f_{l u}^{\prime}}{E_{j}}\right)^{\frac{1}{2}} \\
& \frac{f_{c u}^{\prime}}{f_{c}^{\prime}}=0.5+1.225\left(\frac{f_{l u}^{\prime}}{f_{c}^{\prime}}\right)^{\frac{3}{5}} \\
& \varepsilon_{c u}=0.004325+0.2625\left(\frac{f_{l u}^{\prime}}{f_{c}^{\prime}}\right)\left(\frac{f_{l u}^{\prime}}{E_{j}}\right)^{\frac{1}{2}}
\end{aligned}
$$

Where $f_{t}$ and $\varepsilon_{t}$ are axial stress at the boundary point where the FRP jacket is beginning to get fully activated and corresponding axial strain, respectively. $f_{c u}^{\prime}$ and $\varepsilon_{c u}$ are the ultimate strength of FRP-confined concrete and corresponding ultimate strain, respectively, and $f_{c}^{\prime}$ is the compressive strength of unconfined concrete [14].

And for calculating $f_{l u}^{\prime}$ the effective lateral confining stress at the ultimate condition of FRP jacket, Eq. 7 is used,

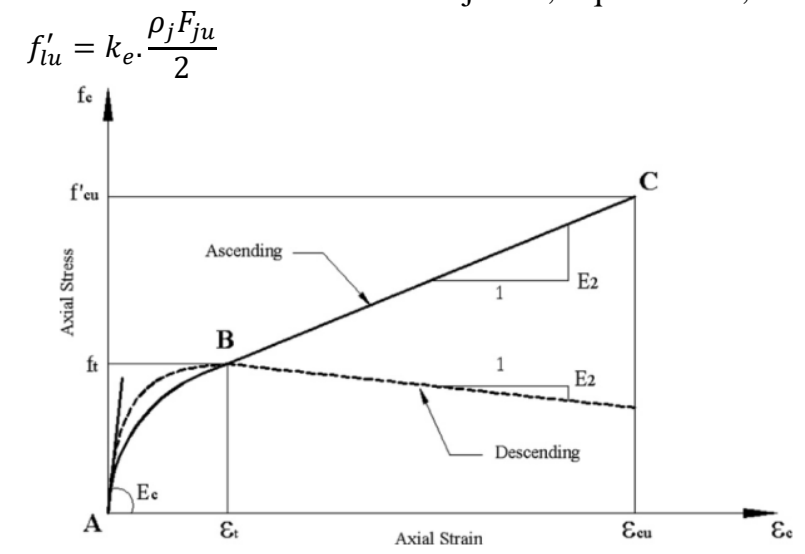

Fig. 3 Proposed model for FRP-confined concrete [14] 
Where $\rho_{j}$ is a volumetric ratio of FRP jacket and could be calculated as $\rho_{j}=4 t_{j} / D$, and $k_{e}$ is the confinement effectiveness coefficient and calculated as,

$$
k_{e}=\frac{1-\left[\frac{\left(b-2 r_{c}\right)^{2}+\left(h-2 r_{c}\right)^{2}}{3 h b}\right]-\rho_{l}}{1-\rho_{l}}
$$

And for the other parameters, $b$ and $h$ are rectangular section measurements, $r_{c}$ is corner radius of rectangular section, $\rho_{l}$, a ratio of longitudinal reinforcement, $D$, a diameter of equivalent circular column and $t_{j}, F_{j u}$ and $E_{j}$ are thickness, tensile strength, and modulus of elasticity of FRP jacket, respectively.

\section{GNU Octave Based Code for Material Model}

In this study, a new code based on GNU Octave program [18] was developed to determine the moment-curvature relationship of square CFRP jacketed RC columns (Fig. 4). The material properties of FRP-confined concrete, FRP and reinforcing steel were used to model the cross-section of CFRP jacketed RC columns. The proposed Yousef et al. material model [14] is selected to model FRP-confined concrete material. A number of assumptions are made in the analysis of CFRP jacketed RC column sections. These assumptions are a) strain distribution is linear, b) concrete and reinforcement steel are fully adhered, c) there is no buckling in longitudinal bars and d) FRP jacket is fully adhered to the surface of the core column.

The "fiber model" technic is used to perform momentcurvature analysis in the developed code. In this technic, sections are divided into multiple fibers, and stresses were calculated based on the uniaxial stress-strain relations for the materials in these fibers (Fig. 5). Equilibrium under axial force and moment was reached be a repeated modification to the strain distribution
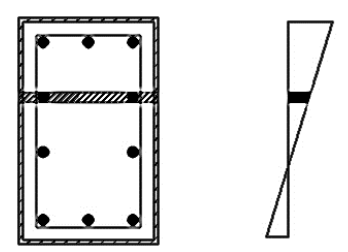

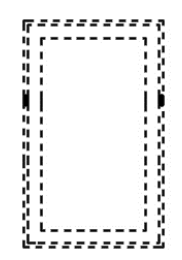

FRP

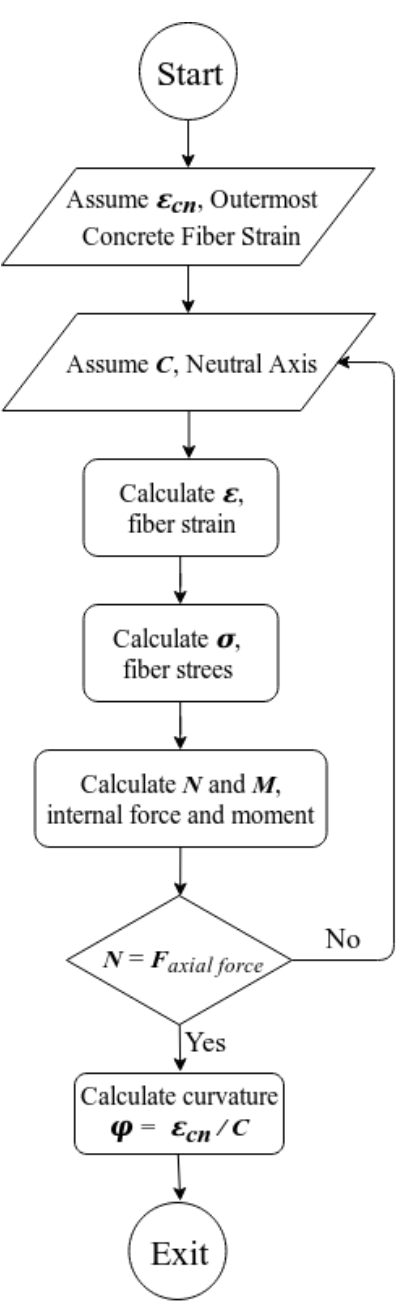

Fig. 4 Flow chart of the developed code

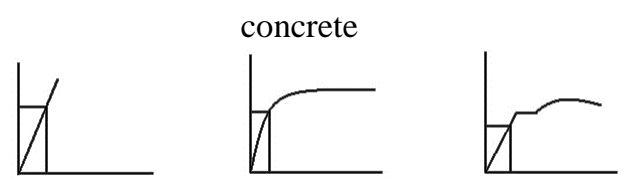

Fig. 5 Fiber model technic to calculate the moment-curvature relationship

The selected material model was compared to the experimental study of You-Yi Wei et al. [19] test results
(Fig. 6). The figure shows that the material model exhibits a very good approach to realistic material behavior. 


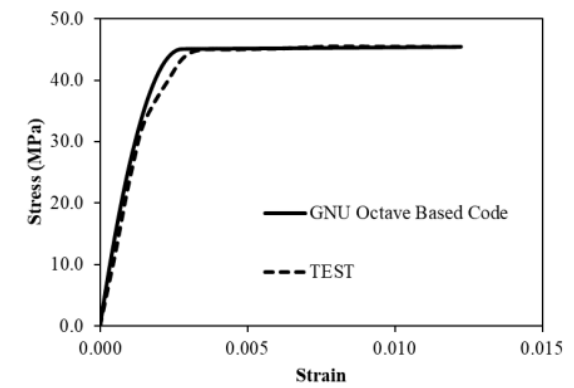

Fig. 6 Material model verification for numerical model with test result [19]

Developed GNU Octave based code was compared with the experimental study of Iacobucci et al. [7] to test the suitability of the developed code to model the behavior of CFRP jacketed RC columns in terms of moment-curvature analyses (Fig. 7). Iacobucci et al. [7] investigated the strengthening of various samples of square columns with CFRP jackets representing RC columns with light transverse reinforcement. Five specimens were chosen for this study, each sample consists of a $305 \times 305$ mm column wrapped with a different number of CFRP layers, details of the specimen's properties are presented in Table 1.

Table 1 Specimens properties from Iacobucci et al. [7]

\begin{tabular}{ccccc}
\hline $\begin{array}{c}\text { Specimen } \\
\text { Name }\end{array}$ & $\begin{array}{c}\text { Concrete } \\
\text { Strength } \\
(\mathrm{MPa})\end{array}$ & $\begin{array}{c}\text { Dim. Of } \\
\text { Columns } \\
(\mathrm{mm})\end{array}$ & $\begin{array}{c}\text { FRP } \\
\text { Thickness } \\
(\mathrm{mm})\end{array}$ & $\begin{array}{c}\text { Axial } \\
\text { Load } \\
(P / \\
\left.f_{c}^{\prime} A_{g}\right)\end{array}$ \\
\hline ASC-2NS & 36.5 & $305 \times 305$ & 1 & 0.38 \\
\hline ASC-3NS & 36.9 & $305 \times 305$ & 2 & 0.65 \\
\hline ASC-4NS & 36.9 & $305 \times 305$ & 1 & 0.65 \\
\hline ASC-5NS & 37.0 & $305 \times 305$ & 3 & 0.65 \\
\hline ASC-6NS & 37.0 & $305 \times 305$ & 2 & 0.38 \\
\hline
\end{tabular}

As seen in Fig. 7, developed code and experimental results from Iacobucci et al. [7] show almost the same behavior. Therefore, and for the purpose of this study, the developed GNU Octave based code can fairly simulate the momentcurvature relationship of CFRP jacketed RC columns and could be used easily to predict the response of this type of elements.

\section{PARAMETRIC STUDY}

A parametric study is performed to examine the momentcurvature relationship of CFRP jacketed RC columns using the developed code. Nonlinear numerical analyses of square RC column with $400 \times 400 \mathrm{~mm}$, 500x500mm, and 600x600m section dimensions are carried out (Fig. 8). In the analysis, the reinforcement ratio and reinforcing steel strength were kept fixed around $1.5 \%$ and $420 \mathrm{MPa}$, respectively.
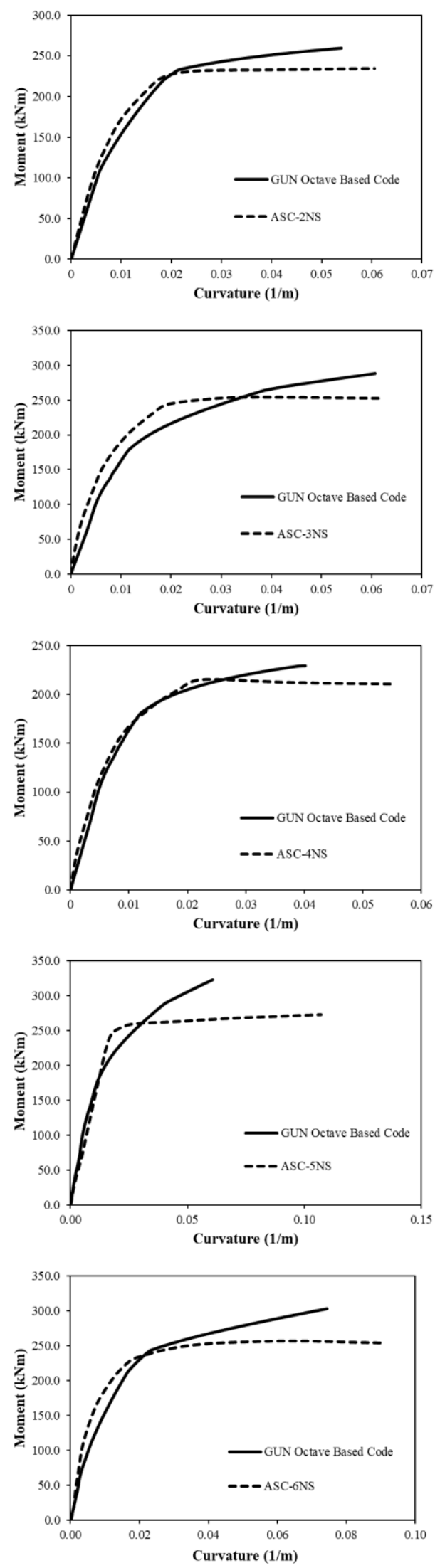

Fig. 7 Verification of numerical models with test results [6] 


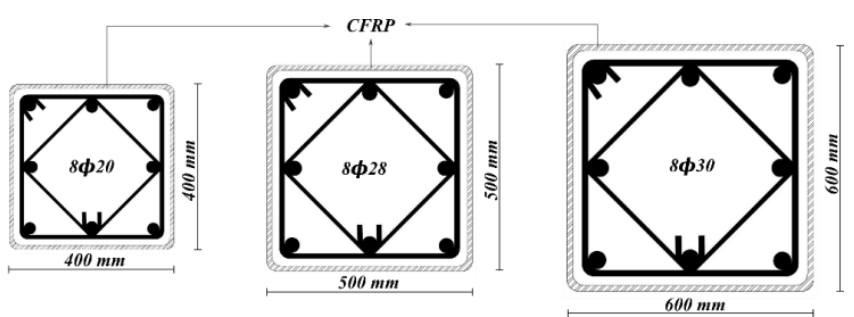

Fig. 8 Details of selected column sections

In addition, three different types of concrete strength, 18, 20 and $30 \mathrm{MPa}$, were used to examine the effect of concrete quality on the behavior of CFRP jacketed RC columns. On the other hand, three different thicknesses, 1,2 and $3 \mathrm{~mm}$, were used in the parametric study to investigate the effect of CFRP thickness on the total response of CFRP jacketed RC columns. CFRP properties were taken as 240GPa for elasticity modulus and $260 \mathrm{MPa}$ for tensile strength.

Moreover, two levels of axial loads were selected to determine moment-curvature relationships for having a better understanding of the response of CFRP jacketed RC columns. Axial load levels are selected as higher $\left(N_{1}=\right.$ $\left.0.50 N_{\max }>N_{b}\right)$ and lower $\left(N_{2}=0.10 N_{\max }<N_{b}\right)$ than balanced point in the axial load-moment interaction diagram. Mander et al. [20] confined concrete model was selected for the non-strength columns which are used for comparison purposes. Where the stress $\left(f_{c}\right)$ and strains $\left(\varepsilon_{c}\right)$ of the

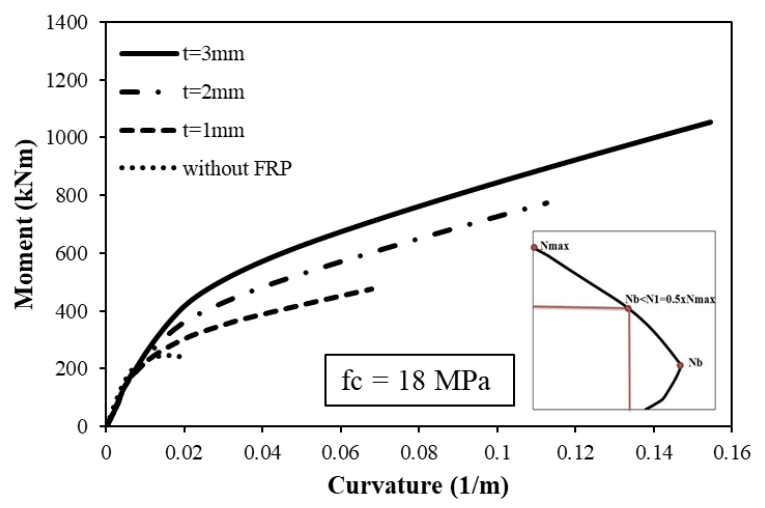

a)

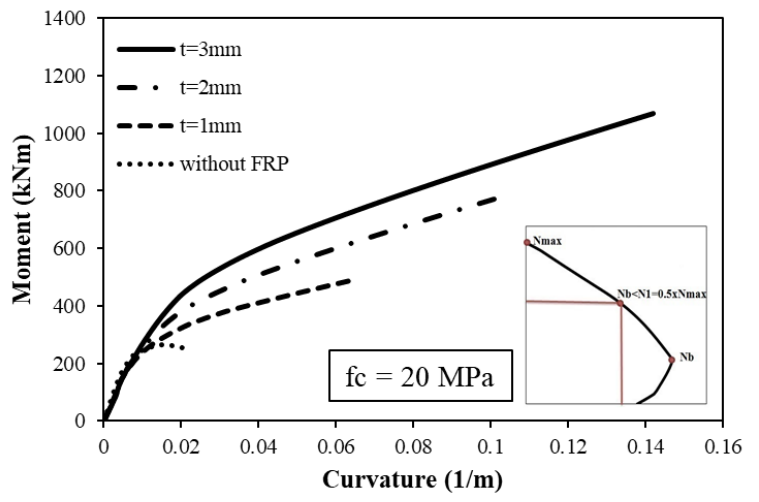

c) confined and unconfined concrete are calculated using Equation (9).

$$
f_{c}=\frac{f_{c c}^{\prime} \frac{\varepsilon_{c}}{\varepsilon_{c c}} r}{r-1+\left(\frac{\varepsilon_{c}}{\varepsilon_{c c}}\right)^{r}}
$$

where $r=E_{c} /\left(E_{c}-E_{s e c}\right)$, with $E_{c}=4700 \sqrt{f_{c o}^{\prime}}$ (in MPa) and $E_{s e c}=f_{c c}^{\prime} / \varepsilon_{c c} . f_{c c}^{\prime}$ and $\varepsilon_{c c}$ are maximum strength and corresponding strain of confined concrete.

As observed from figures 8-10 the stiffness, strength, and ductility of the RC column sections strengthened by CFRP are significantly improved after reinforcement yielding point while CFRP retrofit has a limited effect on the total response of the strengthened column sections before yielding of reinforcement. Furthermore, CFRP jacketed RC columns show a notable ductile behavior compared to the brittle behavior of the non-strengthened column while applying the higher axial load. For example, the ductility is increased 7.4 times for the $400 \times 400 \mathrm{~mm}$ (Fig. 9a) and 5.4 times for the $600 \times 600 \mathrm{~mm}$ sections (Fig. 11a) when concrete strength is $18 \mathrm{MPa}$ and CFRP thickness is $\mathrm{t}=3 \mathrm{~mm}$. Also, the increase in ductility was approximately 5.0 times for the $400 \times 400 \mathrm{~mm}$ (Fig. 9e) and 3.7 times for the 600x600mm sections (Fig. $11 \mathrm{e})$ when concrete strength is $30 \mathrm{MPa}$ and CFRP thickness is $\mathrm{t}=3 \mathrm{~mm}$.

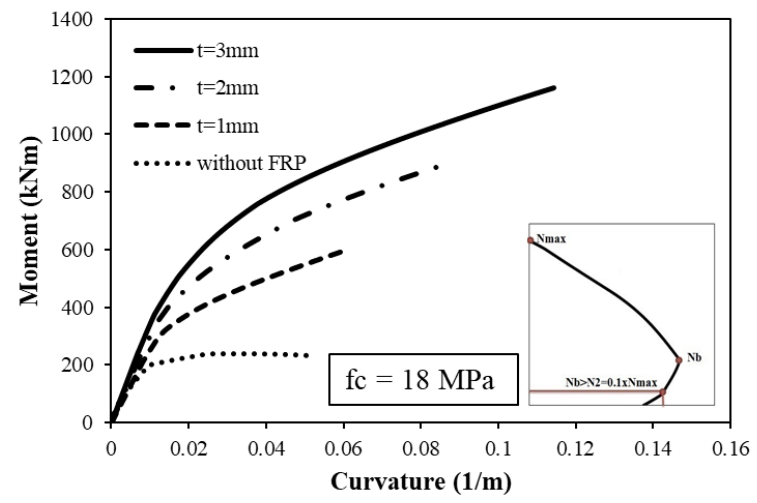

b)

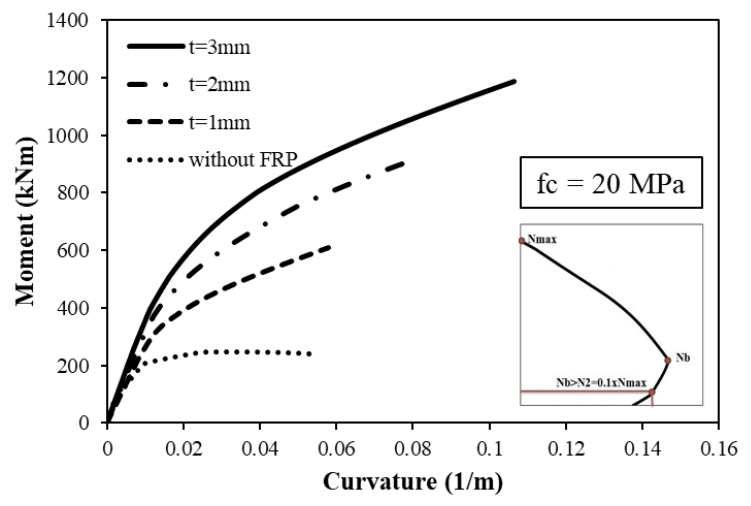

d)

Fig. 9 Moment-Curvature Relationship of CFRP Jacketed RC Columns for 400x400mm sections 


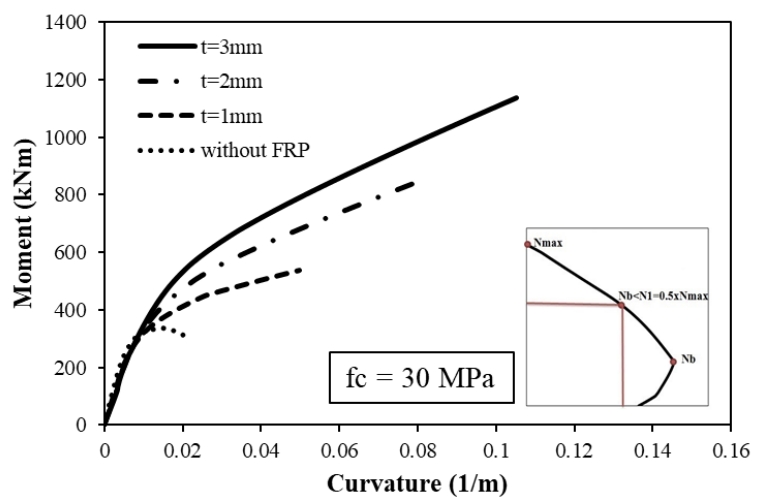

e)

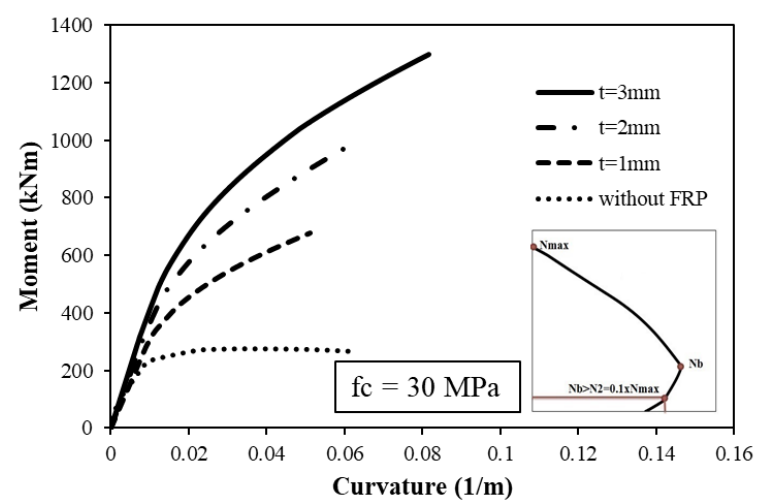

f)

Fig. 9 (con.) Moment-Curvature Relationship of CFRP Jacketed RC Columns for 400x400mm sections

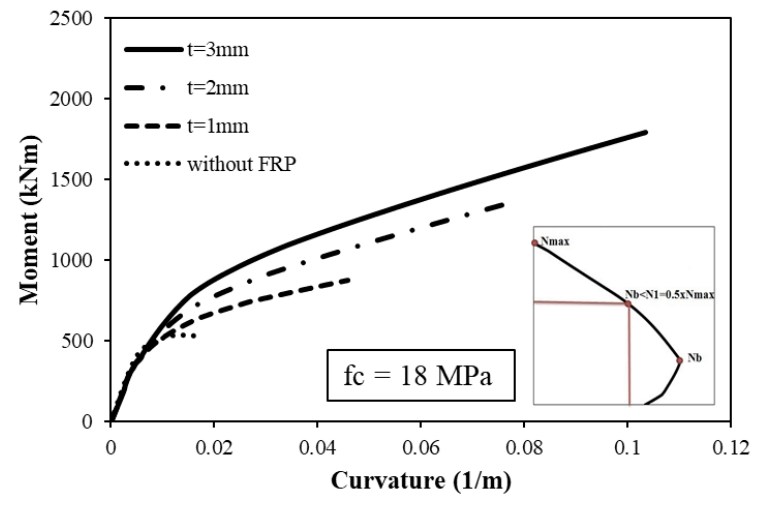

a)

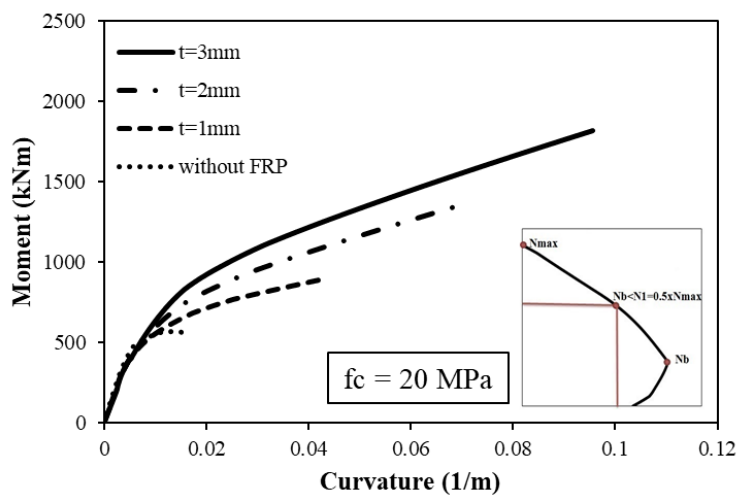

c)

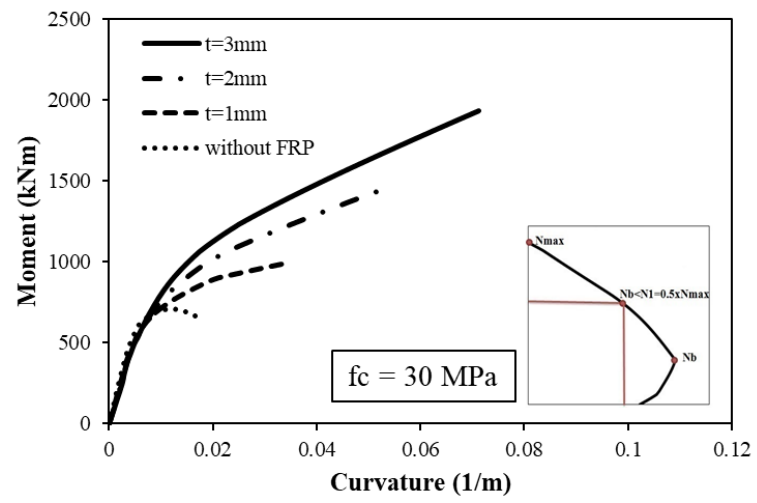

e)

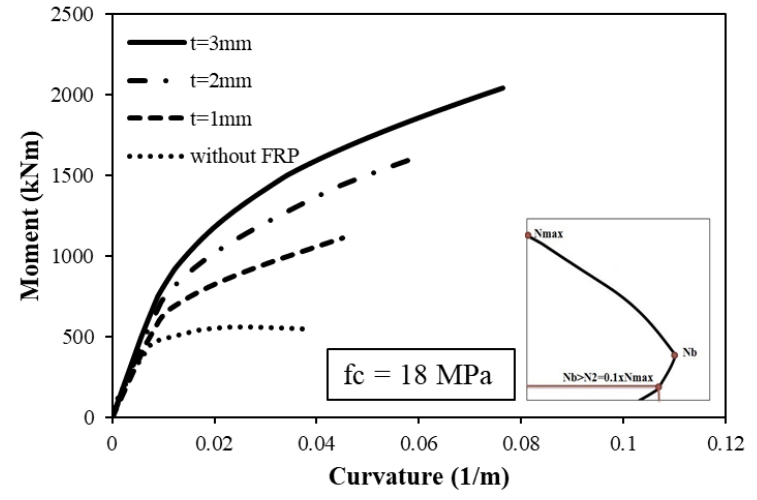

b)

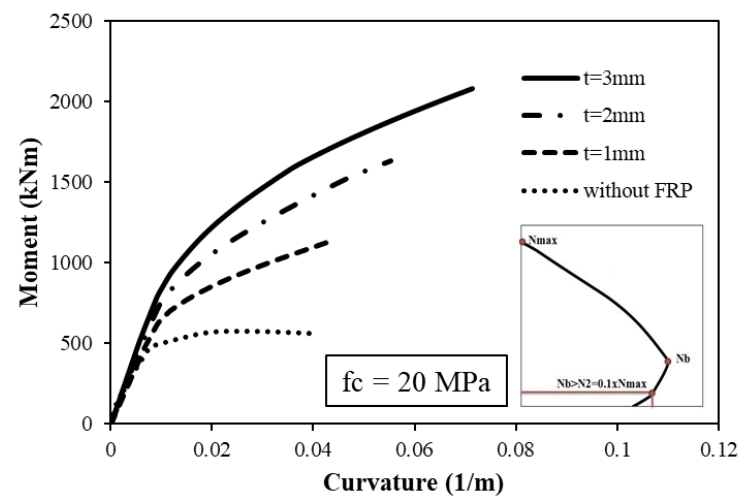

d)

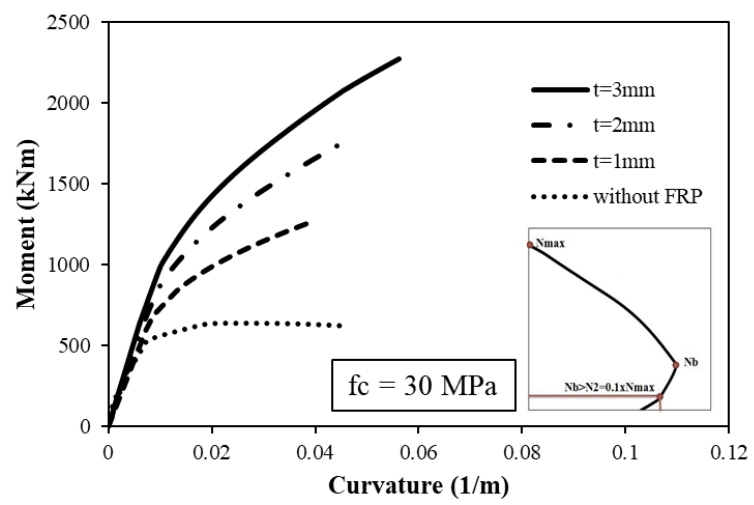

f)

Fig. 10 Moment-Curvature Relationship of CFRP Jacketed RC Columns for 500x500mm sections 


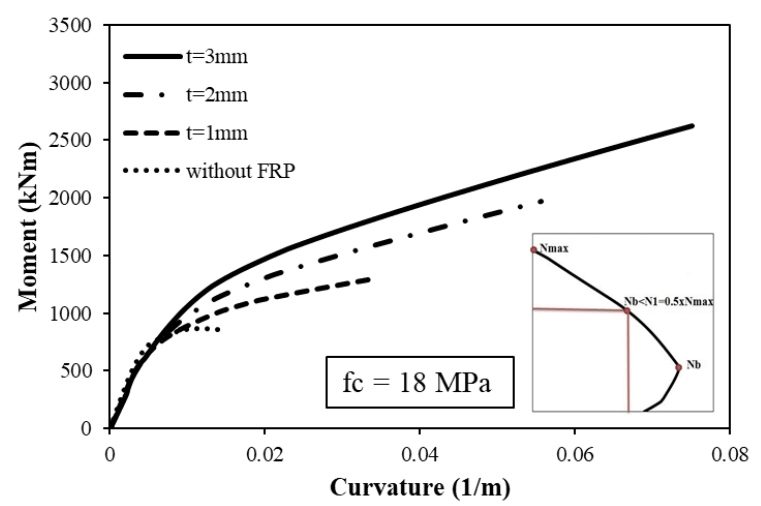

a)

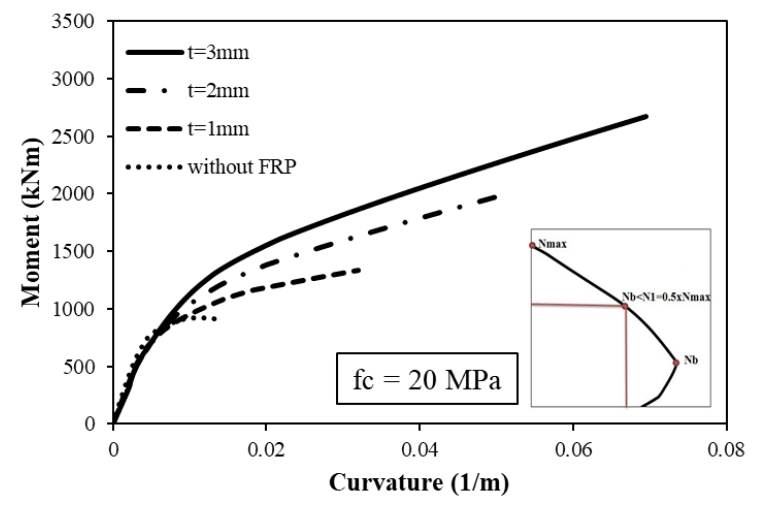

c)

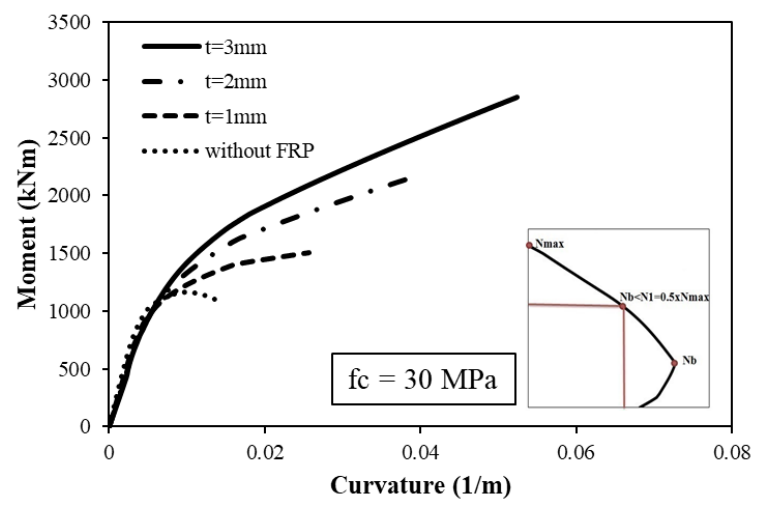

e)

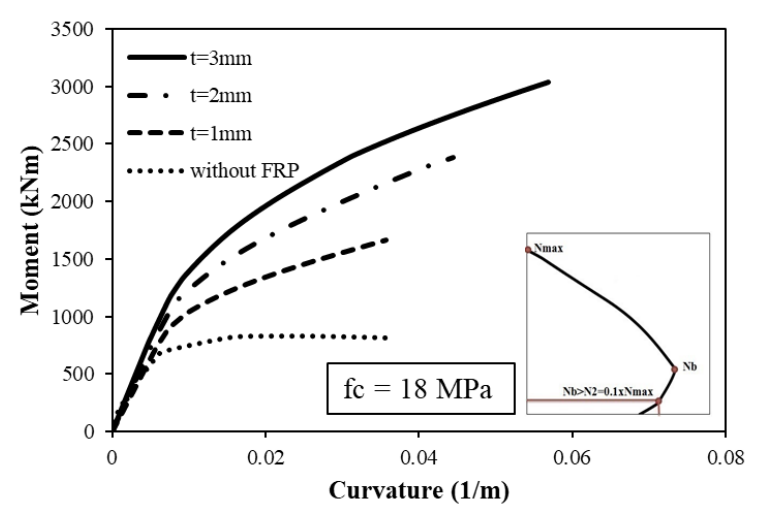

b)

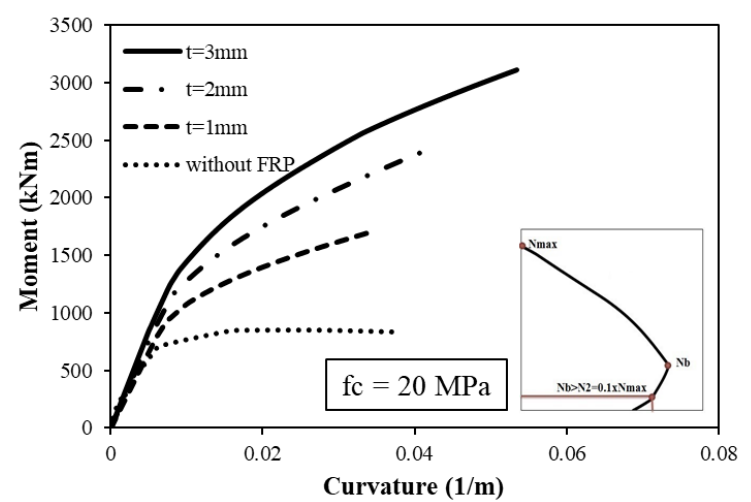

d)

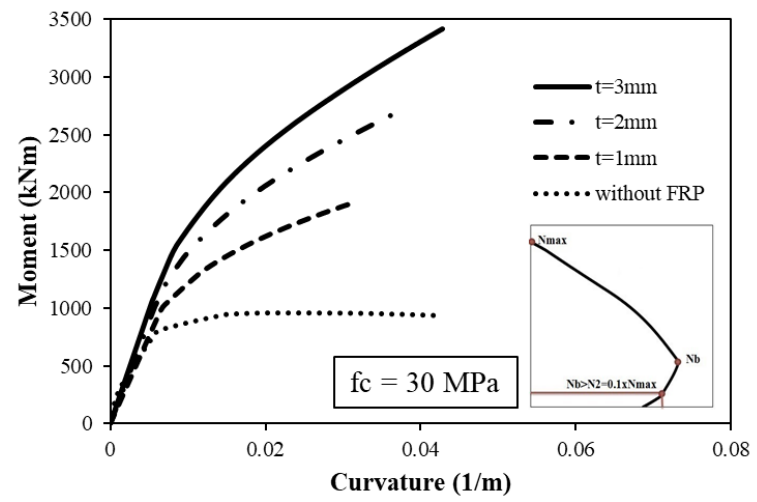

f)

Fig. 11 Moment-Curvature Relationship of CFRP Jacketed RC Columns for 600x600mm sections

As seen from Figures 8-10, non-strengthened RC columns show ductile behavior under lower axial loads below the balanced point. This is why strengthened RC columns show a slight improvement in ductility compared to the nonstrengthened column. For example, the ductility is increased 2.20 times for the $400 \times 400 \mathrm{~mm}$ (Fig. 9b) and 1.60 times for the $600 \times 600 \mathrm{~mm}$ sections (Fig. 11b) when concrete strength is $18 \mathrm{MPa}$ and CFRP thickness is $\mathrm{t}=3 \mathrm{~mm}$. Also, the increase in ductility was approximately 1.30 times for the $400 \times 400 \mathrm{~mm}$ (Fig. 9f) and was around the same value for the $600 \times 600 \mathrm{~mm}$ sections (Fig. 11f) when concrete strength is $30 \mathrm{MPa}$ and GFRP thickness is $\mathrm{t}=3 \mathrm{~mm}$.

The strength capacity of the CFRP jacketed RC columns shows an increase according to the non-strengthened column, also this increase has almost the same levels for both columns with lower and higher axial loads. As seen from figures, lateral load strength capacity increased around 5.00 times for the 400x400mm (Fig. 9a-9b) and around 3.70 times for the $600 \times 600 \mathrm{~mm}$ (Fig. 11a-11b) when concrete strength is $18 \mathrm{MP}$ and GFRP thickness is $\mathrm{t}=3 \mathrm{~mm}$. Also, the increase in strength capacity was approximately 4.90 and 3.70 times for 400x400mm (Fig. 9e-9f) and for the 600x600mm (Fig. 11e$11 \mathrm{f}$ ), respectively, when concrete strength is $30 \mathrm{MPa}$ and CFRP thickness is $\mathrm{t}=3 \mathrm{~mm}$.

Energy dissipation capacities were determined by calculating the areas under moment-curvature curves. The energy dissipation ratio was used to exhibit the improvement of CFRP jacketed RC columns' capabilities to dissipate energy. Energy dissipation capacities of strengthened and non-strengthened RC columns were proportioned to 
determine the energy dissipation ratio. As can be seen clearly from Figures 11-13, CFRP jacketed RC columns with higher axial load levels have greater energy dissipation ratios than columns with lower axial load levels. The reason for that is because non-strengthened RC columns with higher axial load levels have brittle behavior and when these columns wrapped with CFRP, strength capacity and ductility are significantly improved due to confined concrete with CFRP which in turn lead to a higher increase in energy dissipation (Figures 8-10). For example, when concrete strength is considered as $18 \mathrm{MPa}$ the energy dissipation ratios are 5.60 and 26.70 for the $400 \times 400 \mathrm{~mm}$ (Fig. 12a) and, 3.40 and 14.00 for the $600 \times 600 \mathrm{~mm}$ sections (Fig. 14a) with CFRP thickness are $\mathrm{t}=1 \mathrm{~mm}$ and $\mathrm{t}=3 \mathrm{~mm}$, respectively. Also, when concrete strength is considered as 30MPa the energy dissipation ratios are 3.50 and 13.90 for the $400 \times 400 \mathrm{~mm}$ (Fig. 12a) and, 2.30 and 7.80 for the $600 \times 600 \mathrm{~mm}$ sections (Fig. 14a) with CFRP thickness are $\mathrm{t}=1 \mathrm{~mm}$ and $\mathrm{t}=3 \mathrm{~mm}$, respectively. Whereas concrete strength increases the brittle behavior, as expected, become more obvious which affects reduced energy

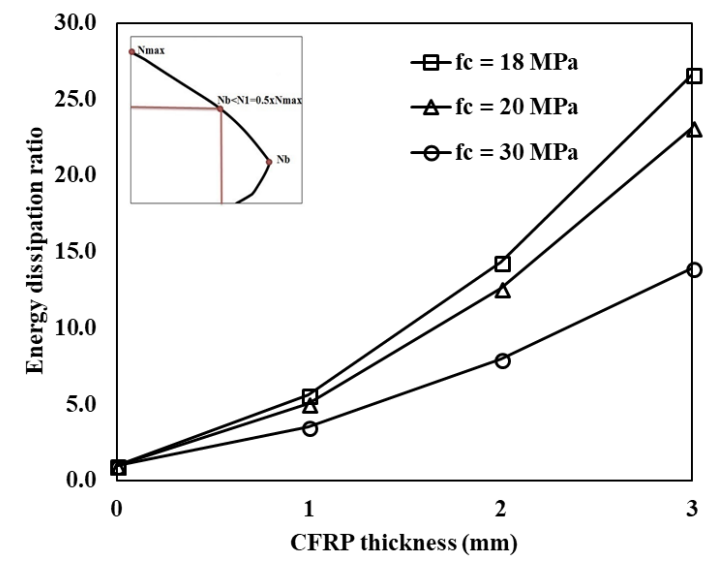

a) dissipation ratios.

On the other hand, columns with lower axial load levels show a small improvement in energy dissipation capabilities compared to columns with higher axial load levels. The reason for this is the ductile behavior of RC columns subjected to axial loads below the balanced point, and thus the level of improvement in ductility of wrapped CFRP columns is very slight. The main reason for energy dissipation capacity increments is related to the notable improved strength capacity of CFRP jacketed RC columns. For example, when concrete strength is considered as $18 \mathrm{MPa}$ the energy dissipation ratios are 2.20 and 8.50 for the $400 \times 400 \mathrm{~mm}$ (Fig. 12b) and, 1.600 and 4.50 for the 600x600mm sections (Fig. 14a) with CFRP thickness are $\mathrm{t}=1 \mathrm{~mm}$ and $\mathrm{t}=3 \mathrm{~mm}$, respectively. Also, when concrete strength is considered as $30 \mathrm{MPa}$ the energy dissipation ratios are 1.50 and 4.60 for the $400 \times 400 \mathrm{~mm}$ (Fig. 12a) and, 1.60 and 2.30 for the $600 \times 600 \mathrm{~mm}$ sections (Fig. 14a) with CFRP thickness are $\mathrm{t}=1 \mathrm{~mm}$ and $\mathrm{t}=3 \mathrm{~mm}$, respectively.

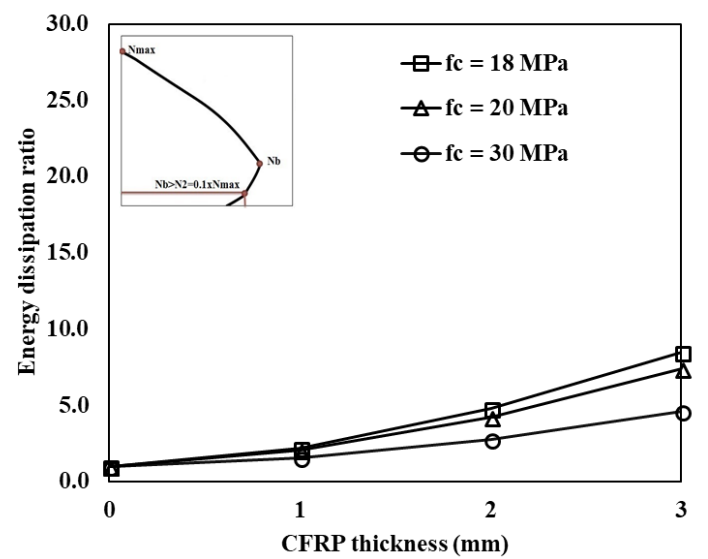

b)

Fig. 12 Energy dissipation ratios correspond to CFRP thickness of strengthened RC Columns for 400x400mm

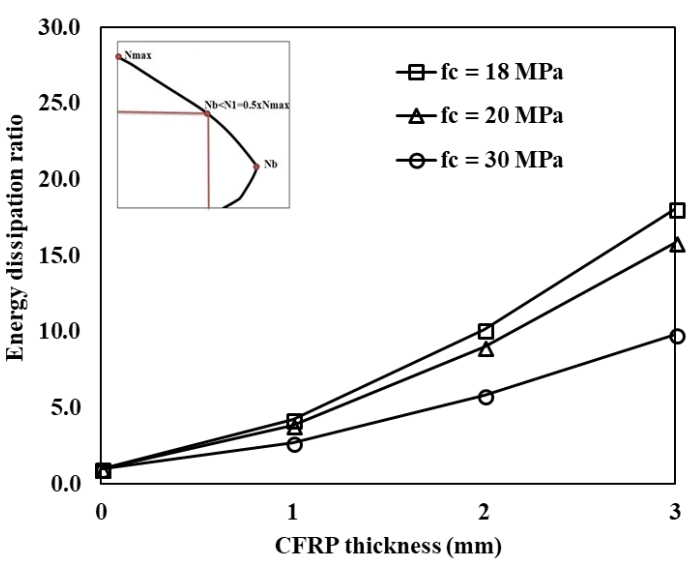

a)

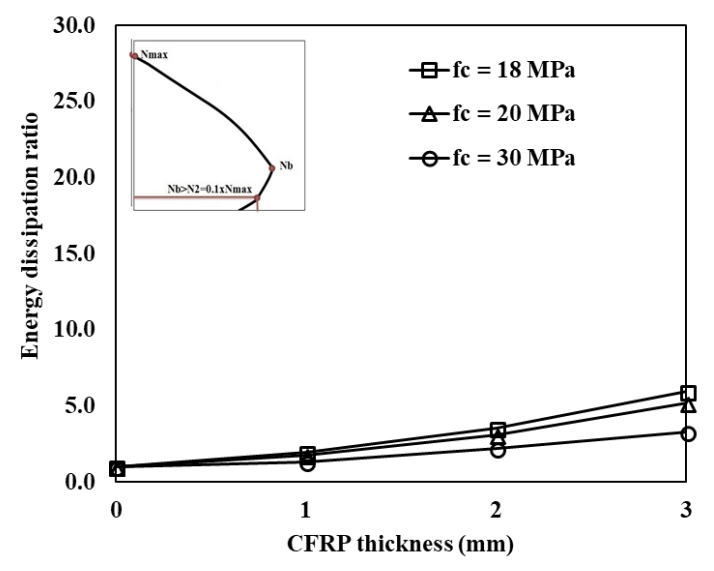

b)

Fig. 13 Energy dissipation ratios correspond to CFRP thickness of strengthened RC Columns for 500x500mm 


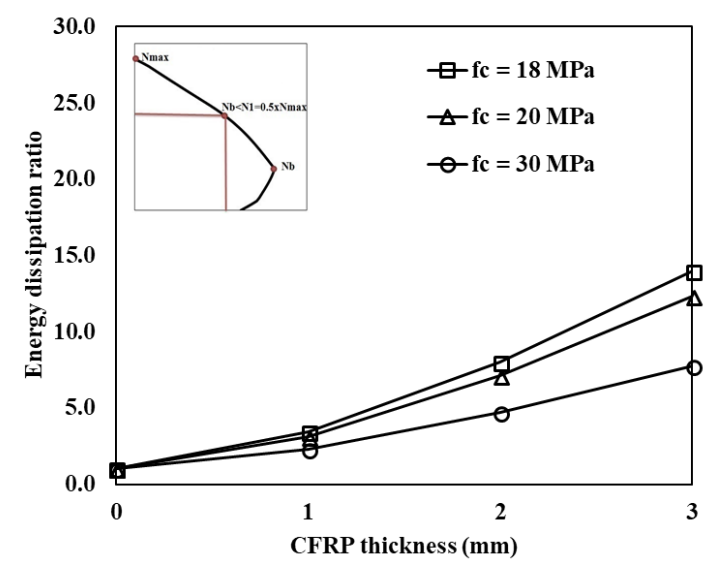

a)

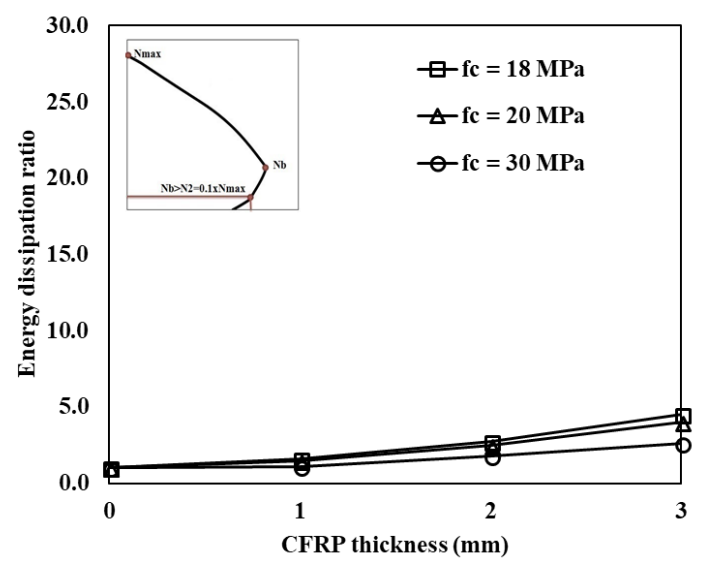

b)

Fig. 14 Energy dissipation ratios correspond to CFRP thickness of strengthened RC Columns for 600x600mm

\section{SUMMARY and CONCLUSIONS}

A parametric study was carried out to examine the effects of CFRP jacketing, axial load levels and concrete quality on responses of strengthened RC columns. The newly computer code was developed to determine moment-curvature relationships of CFRP jacketed RC columns that could describe the capacities of sections in terms of ductility, strength, stiffness and energy dissipation. According to the results of the numerical simulations of CFRP jacketed RC columns and comparison with experimental responses the selected model shows a good agreement between analytical and test results. The parametric study, using different sections, concrete quality, and CFRP thickness, shows that strengthening RC columns with CFRP wraps has a significant effect on the total response of jacketed columns due to the confinement of concrete by the CFRP. The results of the parametric study showed that ductility, stiffness and strength capacity were remarkably increased. While increasing CFRP thickness, the stiffness and strength of CFRP jacketed columns significantly improve for both lower and higher axial load levels. However, the ductility was significantly increased for strengthened columns with higher axial loads above balanced point $\left(N>N_{b}\right)$ where these increments are less notable for lower axial loads $\left(N<N_{b}\right)$. Furthermore, axial load levels also have a great effect on the degree of response enhancement of CFRP jacketed RC columns. This could be clearly noticed from energy dissipation ratios. While columns subjected to axial loads higher than the balanced point have an important energy dissipation capability, the improvement in energy dissipation for columns subjected to axial loads lower than the balanced point is less significant.

\section{REFERENCES}

[1] E. Celebi, M. Aktas, N. Caglar, A. Ozocak, M. Kutanis, N. Mert and Z. Ozcan, "October 23, 2011, Turkey/Van-Ercis earthquake: structural damages in the residential buildings", Natural Hazards, vol. 65, no. 3, pp. 2287-2310, 2013.
[2] J.Z. Wang, J.L Yang, L. Cheng, "Experimental study of seismic behavior of high-strength RC columns strengthened with CFRP subjected to cyclic loading", Journal of Structural Engineering, vol. 145, 2019.

[3] E.D. Castillo, M. Griffith, J. Ingham, "Seismic behavior of RC columns flexurally strengthened with FRP sheets and FRP anchors", Composite Structure, vol. 203, pp. 382-395, 2018.

[4] A. Sarıbıyık, "Effect of Using FRP Composites as Hybrid in the Strengthening of Concretes", Sakarya University Journal of Science vol. 22, no. 2, pp. 383-391, 2018.

[5] P. Juntanalikit, T. Jirawattanasomkul, and A. Pimanmas, "Experimental and numerical study of strengthening nonductile RC columns with and without lap splice by Carbon Fiber Reinforced Polymer (CFRP) jacketing", Engineering Structures, vol. 125, pp. 400-418, 2016.

[6] A. Hosseini, A. R. Khaloo, and S. Fadaee, "Seismic performance of high-strength concrete square columns confined with carbon fiber reinforced polymers (CFRPs)", Canadian Journal of Civil Engineering, vol. 32, pp. 569-578, 2005.

[7] R. D. Iacobucci, S. A. Sheikh, and O. Bayrak, "Retrofit of Square Concrete Columns with Carbon Fiber-Reinforced Polymer for Seismic Resistance", ACI Structural Journal, vol. 100, no. 6, pp. 785-794, 2003.

[8] P. Faustino, P. Frade, and C. Chastre, "Lateral cyclic behavior of RC columns confined with carbon fibres", Structures, vol. 5, pp. 196-206, 2016.

[9] H. Nakahara and H. Yin, "Self-centering capacity of a structural Frame composed of steel-jacketed concrete columns and steel beams", Structures, vol. 14, pp. 409-415, 2018.

[10] Y. H. Chai, M. J. N. Priestley and F. Seible, "Flexural retrofit of circular reinforced concrete bridge columns by steel jacketing - experimental studies", Report No. SSRP91/06, San Diego, University of California, 1991.

[11] G. E. Thermou, V. K. Papanikolaou and A. J. Kappos, "Flexural behavior of reinforced concrete jacketed columns under reversed cyclic loading", Engineering Structures, vol. 76, pp. 270-282, 2014.

[12] M. Soman and J. Mohan, "Rehabilitation of RC 
columns using ferrocement jacketing", Construction and Building Materials, vol. 181, pp. 156-162, 2018.

[13] A. Kaish, M. R. Alam, M. Jamil, M. F. M. Zain and M. A. Wahed, "Improved ferrocement jacketing for restrengthening of square RC short column", Construction and Building Materials, vol. 36, pp. 228-237, 2012.

[14] M. N. Youssef, M. Q. Feng, and A. S. Mosallam, "Stress-strain model for concrete confined by FRP composites", Composites: Part B, vol. 38, pp. 614-628, 2007.

[15] L. Lam and J. G. Teng, "Stress-strain model for FRPconfined concrete under cyclic axial compression", Engineering Structures, vol. 31, no. 2, pp. 308-321, 2009.

[16] U. Ersoy and G. Ozcebe, Reinforced Concrete, Department of Civil Engineering, Middle East Technical
University, METU Press, Ankara, 2008.

[17] U. Ersoy and G. Ozcebe, "Moment-curvature relationship of confined concrete sections", Technical Journal of Turkish Chamber of Civil Engineers, vol. 9, no. DEC., pp. 549-553, 1998.

[18] J. W. Eaton, D. Bateman, S. Hauberg, and R. Wehbring, GNU Octave version 4.2.1 manual: a high-level interactive language for numerical computations, http://www.gnu.org/software/octave/doc/interpreter/, 2017. [19] Y. Y. Wei and Y. F. Wu, "Unified stress-strain model of concrete for FRP-confined columns", Construction and Building Materials, vol. 26, no. 1, pp. 381-392, 2012.

[20] J. B. Mander, M. J. N. Priestley, and R. Park, "Theoretical Stress-Strain Model for Confined Concrete", Journal of Structural Engineering, vol. 114, no. 8, pp. 1804 1826, Sep. 1988. 